\title{
Hydration, Strength and pH Properties of Porous Concrete Using Rice Husk Ash
}

\author{
Kim, Young Ik* Sung, Chan Yong**,†
}

\begin{abstract}
This study was performed to evaluate void ratio, compressive and flexural strengths, and $\mathrm{pH}$ properties according to the content ratio of rice husk ash, aggregate size, and neutral treatment time of porous concrete with content of rice husk ash produced as an agricultural by-product. The SEM results for cement mortar with a $5 \%$ rice husk ash for the weight of cement formed more $\mathrm{C}-\mathrm{S}-\mathrm{H}$ hydrates due to the $\mathrm{SiO}_{2}$ of rice husk ash. In the $\mathrm{XRD}$ test, cement mortar with a $5 \%$ rice husk ash for the weight of cement registered a higher peak point of approximately $2 \theta=20 \sim 25^{\circ}$ compared to cement mortar without rice husk ash. According to the results of the $\mathrm{XRD}$ and SEM tests, the $\mathrm{SiO}_{2}$ that was a major chemical element of rice husk ash generated a large amount of calcium hydroxide in the early stage of the hydration process of cement leading to the formation of ettringite. The void ratio of porous concrete with rice husk ash decreased with increasing content ratio of rice husk ash. In addition, the void ratio of porous concrete with rice husk ash decreased compared to porous concrete without rice husk ash. The compressive and flexural strength of porous concrete with a $5 \%$ and $10 \%$ content ratio of rice husk ash slightly increased compared to concrete without rice husk ash. The $\mathrm{pH}$ value of porous concrete rapidly decreased immediately after neutral treatment. Then, it gradually increased and decreased again after 14 days. However, the $\mathrm{pH}$ value was nearly the same regardless of neutral treatment time in 28 curing days. Also, for neutral treatment, the $\mathrm{pH}$ value of porous concrete showed appropriate $\mathrm{pH}$ levels (less than 9.5) in all mixtures for planting at 28 curing days.
\end{abstract}

Keywords : Rice husk ash, Porous concrete, Neutral treatment, SEM, XRD, Void ratio

\section{Introduction}

Although concrete has contributed to the economic and cultural development of social infrastruc-

* Institute of Agricultural Science, Chungnam National University

** Professor, Division of Bio-Resources Engineering, College of Agriculture and Life Sciences, Chungnam National University

† Corresponding author. Tel.: +82-42-821-5798

Fax: +82-42-821-8877

E-mail address: cysung@cnu.ac.kr tures, civil engineering, and architectural structures, including roads, railways, harbors, and water supply and drainage, it has had a negative impact on the environment destroyirg forests, nature, and disturbing the natural habitation of animals and plants while pursuing its ultimate. Therefore, concrete has been fabricated in recent years as a porous product to address these problems and can be found in various applications, such as sound absorption, permeability, planting, and water purification. In addition, studies have been actively 
conducted on the use of bottom ash and sewer sediment, recycling of fly ash and waste paint, and substitution of slag to suppress the discharge of $\mathrm{CO}_{2}$, a major factor contributing to global warming, and reduce environmental loads in the production of cement. ${ }^{3,12)}$

In particular, studies on planting concrete have become important regarding the void of porous concrete used in planting, water retention insulators used to supply water and nutrients, and soil dressing on concrete used to aid seed development.

In addition, rice husk produced in the hulling of rice is approximately 900,000 tons per year, but has only been considered an agricultural byproduct. The internal and external skin of rice husk is densely covered with silica and can be used as a high value added product. The major element of rice husk ash produced at a specific temperature is composed of $\mathrm{SiO}_{2}$ and is similar to the silica fume used as content agent. Therefore, rice husk ash may be used as a substitution material for content agents to develop high performance concrete of high strength and high durability (Sung et al., 1996).

Park et al. showed that the compressive strength of concrete with optimum content ratio of rice husk ash was $11 \sim 20 \%$ higher than normal concrete and optimum content ratio of rice husk ash was $10 \%, 10 \%$ and $5 \%$ of cement weight at the unit cement contents $400 \mathrm{~kg} / \mathrm{m}^{3}, 500 \mathrm{~kg} / \mathrm{m}^{3}$ and $600 \mathrm{~kg} / \mathrm{m}^{3}$. respectively. Also, The resistance of concrete with rice husk ash that contain air content $4 \sim 7 \%$ for freezing and thawing had high durability factor in both cases of steam curing and standard curing. ${ }^{11)}$

Thus, it is necessary to conduct further research in order to increase incomes in the agricultural industry. $^{2,9)}$

This study developed porous concrete that uses rice husk ash as a substitution material for admixture agents and investigated the various characteristics of this concrete, such as hydration, $\mathrm{po}^{-}$ rosity, compressive strength, flexural strength, and $\mathrm{pH}$, according to the aggregate size and content ratio of rice husk ash. In addition, this study introduces practical information on how to apply this concrete as planting concrete blocks to protect inclined planes.

\section{Materials and methods}

\section{Materials}

The cement used in this study was a regular product of Portland cement by S Company in Korea, guaranteed by the KS F 5201. Crushed stone was used as a coarse aggregate. After burning rice husk, rice husk ash was converted into particles. In addition, a high performance water reducing agent applied to increase the strength of porous concrete and guarantee fluidity. Furthermore, ammonium biphosphate $\left[\left(\mathrm{NH}_{4}\right)_{2} \mathrm{HPO}_{4}\right.$, purity: $99.1 \%, \mathrm{pH}: 8.14$ ] was used as a neutralization agent in order to suppress the leaching of alkali from porous concrete.

Tables 1, 2, 3 and 4 show the physical and chemical characteristics of these components.

Table 1 Chemical compositions of normal Portland cement (unit: \%)

\begin{tabular}{c|c|c|c|c|c|c|c}
\hline $\mathrm{SiO}_{2}$ & $\mathrm{Al}_{2} \mathrm{O}_{3}$ & $\mathrm{CaO}$ & $\mathrm{MgO}$ & $\mathrm{SO}_{3}$ & $\mathrm{~K}_{2} \mathrm{O}$ & $\mathrm{Na}_{2} \mathrm{O}$ & $\mathrm{Fe}_{2} \mathrm{O}_{3}$ \\
\hline 21.09 & 4.84 & 63.85 & 3.32 & 3.09 & 1.13 & 0.29 & 2.39 \\
\hline
\end{tabular}

Table 2 Physical properties of coarse aggregate

\begin{tabular}{c|c|c|c|c|c}
\hline Item & $\begin{array}{c}\text { Size } \\
(\mathrm{mm})\end{array}$ & $\begin{array}{c}\text { Specific } \\
\text { gravity }\left(20^{\circ} \mathrm{C}\right)\end{array}$ & $\begin{array}{c}\text { Absorption } \\
(\%)\end{array}$ & $\begin{array}{c}\text { Fineness } \\
\text { modulus }\end{array}$ & $\begin{array}{c}\text { Unit } \\
\text { weight }\left(\mathrm{kg} / \mathrm{m}^{3}\right)\end{array}$ \\
\hline Coarse & $5 \sim 10$ & 2.57 & 2.64 & 6.64 & 1,457 \\
\cline { 2 - 6 } aggregate & $10-20$ & 2.44 & 2.58 & 6.32 & 1,443 \\
\hline
\end{tabular}


Table 3 Physical properties of rice husk ash

\begin{tabular}{c|c|c|c|c|c}
\hline Specific & Unit weight & $\begin{array}{c}\text { Blain } \\
\text { gravity } \\
\left(20^{\circ} \mathrm{C}\right)\end{array}$ & \multicolumn{3}{|c}{ Grain size $(\mathrm{\mu m})$} \\
\cline { 4 - 6 }$\left(\mathrm{kg} / \mathrm{m}^{3}\right)$ & $\left(\mathrm{cm}^{2} / \mathrm{g}\right)$ & $90 \%$ pass & $50 \%$ pass & $10 \%$ pass \\
\hline 2.32 & 412 & 3,888 & 88.3 & 17.9 & 0.9 \\
\hline
\end{tabular}

Table 4 Chemical compositions of rice husk ash

\begin{tabular}{c|c|c|c|c|c|c|c|c}
\hline $\mathrm{SiO}_{2}$ & $\mathrm{CaO}$ & $\mathrm{MgO}$ & $\mathrm{K}_{2} \mathrm{O}$ & $\mathrm{Na}_{2} \mathrm{O}$ & $\mathrm{Al}_{2} \mathrm{O}_{3}$ & $\mathrm{Fe}_{2} \mathrm{O}_{3}$ & $\mathrm{SO}_{3}$ & Ig.loss \\
\hline 82.50 & 0.90 & 0.50 & 1.40 & 0.10 & 0.20 & 0.10 & 0.10 & 9.20 \\
\hline
\end{tabular}

\section{Mixture design and fabrication}

The mixture of porous concrete for planting is necessary to secure a suitable void size and continuous void ratio to take root in the concrete in order to grow various plants. Thus, the mixture design was configured to a compressive strength of 6 $10 \mathrm{MPa}$ and void of $25-40 \%$ in 28 curing days.

The unit amounnt of binder was defined as $260 \mathrm{~kg} / \mathrm{cm}^{2}$ and an aggregate size of $5 \sim 10 \mathrm{~mm}$ and $10 \sim 20 \mathrm{~mm}$ was prepared to grow various plants in porous concrete blocks. In addition, $0 \%, 5 \%, 10 \%$, and $15 \%$ ratios of rice husk ash were used regarding the weight of the cement in order to improve the strength of the concrete using this agriculture by-product.

High performance water reducing agent was used to increase the strength and guarantee fluidity of the concrete. Table 5 shows the mixture design in this case.

The porous concrete was fabricated based on the KS F 2405 compressive strength of a concrete test method by applying a mixture process where thick aggregates, cement, and rice husk ash were applied and mixed for 30 seconds to perform dry mixing. Then, a water and high performance water reducing agent were applied to this mixture, mixed for 1 minute, and hardened with vibrations for 30 seconds after placing it into a mold. The mixture was cured in a curing box (temperature: $21^{\circ} \mathrm{C}$, moisture: $96 \pm 2 \%$ ) for 24 hours and was separated to place it in water $\left(21^{\circ} \mathrm{C}\right)$ for a specific number of hours. Specimens prepared in a surface dried saturated state were steeped in a $10 \%$ of ammonium biphosphate solution for 10 minutes in order to prevent the leaching of alkali from porous concrete. Furthermore, the neutralization treatment time was applied over four different curing periods of 1 day, 6 days, 13 days, and 24 days, to measure the change in $\mathrm{pH}$ according to the neutralization time.

\section{Test methods}

An SEM (scanning electronic microscope) projects electron beams onto the surface of a specimen

Table 5 Mixture design of porous concrete using rice husk ash for planting

\begin{tabular}{|c|c|c|c|c|c|c|c|c|}
\hline Series & $\begin{array}{l}\text { Mix } \\
\text { type }\end{array}$ & $\begin{array}{c}\text { Coarse } \\
\text { aggregate } \\
\text { size (mm) }\end{array}$ & Cement & $\begin{array}{c}\text { Crushed } \\
\text { aggregate }\end{array}$ & $\begin{array}{c}\text { Rice } \\
\text { husk } \\
\text { ash }\end{array}$ & W & $\begin{array}{l}\text { W/B } \\
(\%)\end{array}$ & $\begin{array}{c}\text { Water reducing } \\
\text { agent }\end{array}$ \\
\hline \multirow{4}{*}{$\begin{array}{l}\text { Series } \\
\mathrm{I}-1\end{array}$} & $\mathrm{RPCO}$ & \multirow{4}{*}{$5 \sim 10$} & 260.0 & 1,963 & 0 & 52.0 & 20 & 2.60 \\
\hline & RPC5 & & 247.0 & 1,963 & 13 & 52.0 & 20 & 2.86 \\
\hline & $\mathrm{RPC10}$ & & 234.0 & 1,963 & 26 & 57.2 & 22 & 3.38 \\
\hline & RPC15 & & 221.0 & 1,963 & 39 & 62.4 & 24 & 3.90 \\
\hline \multirow{4}{*}{$\begin{array}{c}\text { Series } \\
\mathrm{I}-2\end{array}$} & $\mathrm{RPCO}$ & \multirow{4}{*}{$10 \sim 20$} & 260.0 & 1,984 & 0 & 52.0 & 20 & 2.60 \\
\hline & RPC5 & & 247.0 & 1,984 & 13 & 52.0 & 20 & 2.86 \\
\hline & $\mathrm{RPC10}$ & & 234.0 & 1,984 & 26 & 57.2 & 22 & 3.38 \\
\hline & $\mathrm{RPCl} 15$ & & 221.0 & 1,984 & 39 & 62.4 & 24 & 3.90 \\
\hline
\end{tabular}


to detect various signals from the specimen and can be applied to obtain information on the type and structure of a target object. Mortar was fabricated to analyze the characteristics of hydration according to the content ratio of rice husk ash in which the specimen, which was cut in the 28 curing day, and was measured at a magnification of 5,000 using an SEM. An XRD is a device that determines the crystal structure of minerals or solid objects and analyzes the crystallinity of atomic orientation using their crystal structures. In addition, it quantitatively analyzes the composition ratio of such objects. In order to analyze the material produced due to hydration in relation to the content ratio of rice husk ash, cement mortar was fabricated. Void ratio tests were applied using a $\emptyset 10 \times 20 \mathrm{~cm}$ specimen based on the void test method of porous concrete defined by the Eco Concrete Research Committee of the Japan Concrete Institute. The following equation was used in these tests.

$$
P_{o}=\left\{1-\frac{W_{2}-W_{1}}{V}\right\} \times 100
$$

where $P_{o}$ is the void of concrete (\%), $W_{1}$ is the weight of the specimen in water $(\mathrm{g}), W_{2}$ is the weight of the air-dried curing specimen $(\mathrm{g})$, and $V$ is the volume of the specimen $\left(\mathrm{cm}^{3}\right)$.

Compressive strength tests were applied based on the KS F 2405 compressive concrete strength test method using a $\emptyset 7.5 \times 15 \mathrm{~cm}$ specimen, which was cured for 7 and 28 days. Flexural strength tests were applied based on the KS F 2408 flexural concrete strength test method using a $6 \times 6 \times 24 \mathrm{~cm}$ specimen, which was cured for 7 and 28 days. Furthermore, $\mathrm{pH}$ tests were applied using a $5 \times 5 \times 5 \mathrm{~cm}$ specimen that was steeped in distilled water for 1 day and was five times lager than the volume of the specimen. The device used in these $\mathrm{pH}$ tests consisted of glass electrodes and comparative electrodes.

\section{Results and Discussions}

\section{Microstructure of cement mortar by SEM}

SEM were applied to analyze characteristics of hydration according to $0 \%, 5 \%, 10 \%$, and $15 \%$ content ratio of rice husk ash for the weight of cement. Photo 1(a) illustrates the microstructure of cement mortar without rice husk ash. According to the results from the hydration process, the microstructure of cement mortar indicated a large formation of ettringite and $\mathrm{C}-\mathrm{S}-\mathrm{H}$ hydrates along with the presence of calcium hydroxide that was processed in hydration.

Photo 1(b) shows the microstructure of cement mortar with a $5 \%$ content ratio of rice husk ash for the weight of cement. According to the results from the hydration process, high levels of $\mathrm{C}-\mathrm{S}-\mathrm{H}$ hydrates and ettringite were present due to $\mathrm{SiO}_{2}$ in the applied rice husk ash. In addition, some the microstructure of cement mortar remained in a non-hydration state in cement paste.

Photo 1(c) shows the microstructure of cement mortar with a $10 \%$ content ratio of rice husk ash for the weight of cement. According to the results from the hydration process, high levels of $\mathrm{C}-\mathrm{S}-\mathrm{H}$ hydrates and ettringite were present due to $\mathrm{SiO}_{2}$ of rice husk ash compared to mortar without rice husk ash. In addition, some the microstructure of cement mortar demonstrated some porosity and remained in a non-hydration state due to the increase in the mixing ratio of water and cement.

Photo 1(d) shows the microstructure of cement mortar with a $15 \%$ rice husk ash content for the weight of cement. According to the results from the hydration process, high levels of $\mathrm{C}-\mathrm{S}-\mathrm{H}$ hydrates and ettringite were present due to the large amount of rice husk ash. In addition, some 


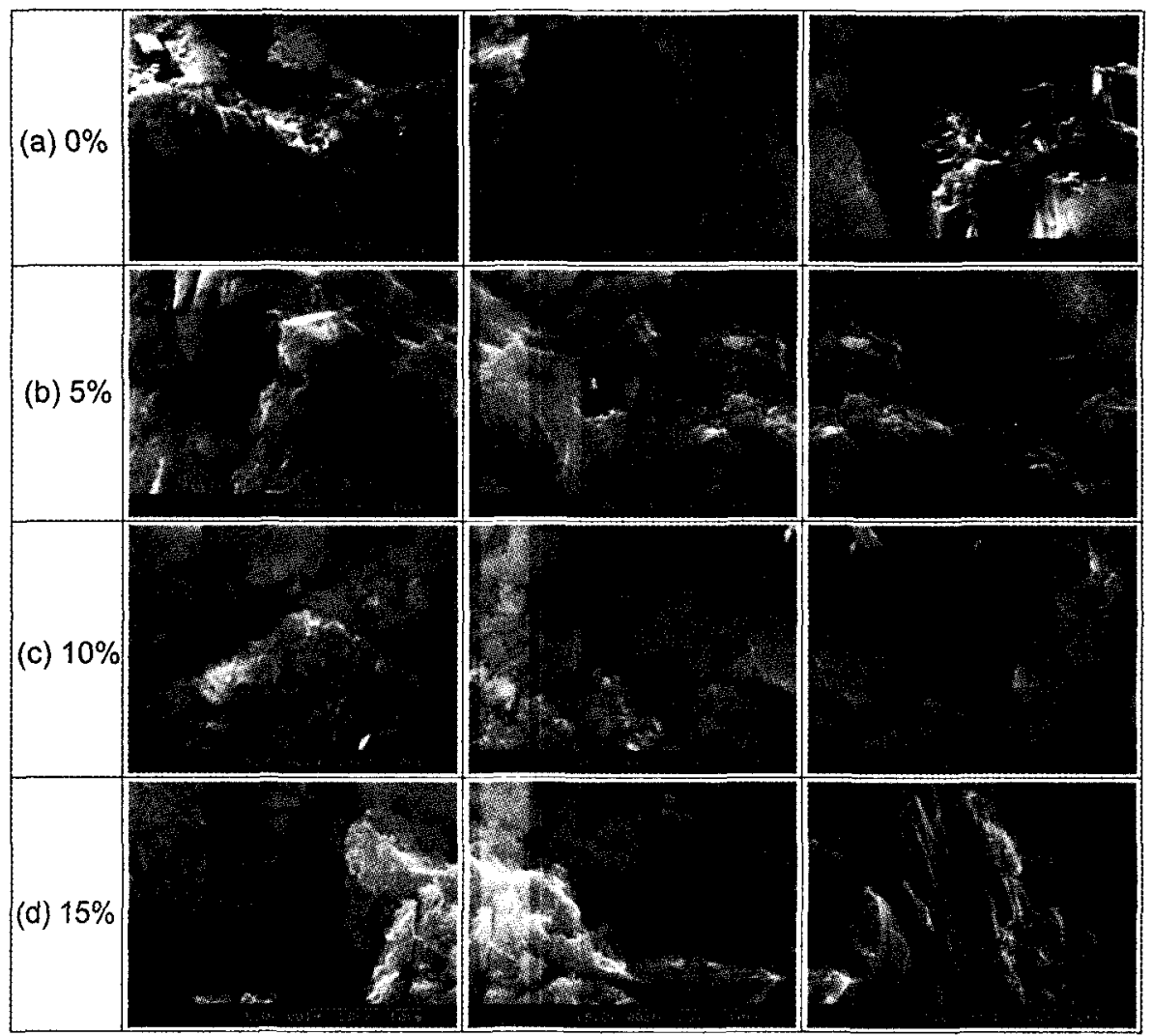

Photo 1 Microstructure of cement mortar with content ratio of rice husk ash by SEM

of the microstructure of cement mortar remained in a non-hydration state and were present in internal porosity due to the increase in the $\mathrm{mix}^{-}$ ing ratio of water and cement. ${ }^{2,9)}$

\section{Hydration analysis by $\mathrm{X}$-ray diffraction}

$X$-ray diffraction tests were applied to analyze the production of hydrates in cement paste for 28 curing days according to the content ratio of rice husk ash. Fig. 1(a) and (b) illustrate the results of the $\mathrm{XRD}$ of cement and rice husk ash.

According to the results of the XRD of cement, it was evident that various components, such as $\mathrm{SiO}_{2}$ and $\mathrm{CaO}$, existed. Furthermore, according to the results of the XRD of rice husk ash, the $\mathrm{SiO}_{2}$ element was observed as a major component due to a peak that registered approximately $2 \theta$ $=20 \sim 25^{\circ}$.

Fig. 1(c) $\sim(\mathrm{f})$ illustrate the results of the XRD of cement mortar with a $0 \%, 5 \%, 10 \%$, and $15 \%$ content ratio of rice husk ash.

According to the results of the XRD test of cement mortar in connection with the content ratio of rice husk ash, cement mortar with a $5 \%$ and $10 \%$ rice husk ash mixture demonstrated higher peaks of approximately $2 \theta=15 \sim$ $20^{\circ}$ and $2 \theta=30 \sim 35^{\circ}$, respectively. This showed that a large amount of calcium hydroxide and calcium carbonate that significantly affected hydration was present in these mortars. ${ }^{2,9}$ However, cement mortar with a $15 \%$ content ratio of rice husk ash represented a small amount of calcium hydroxide and calcium carbonate compared to 


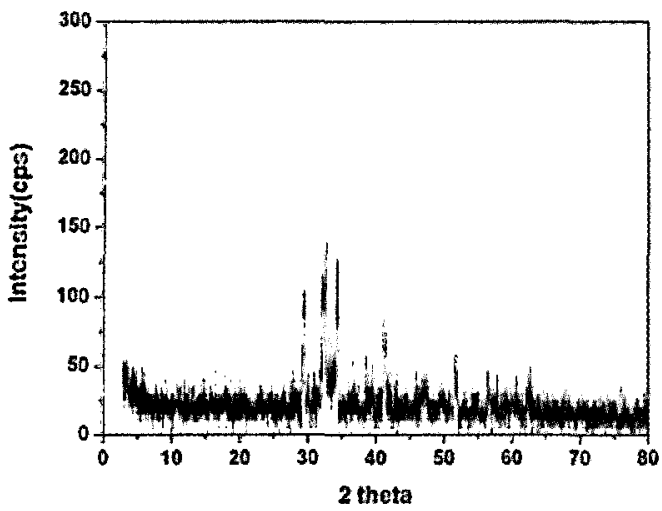

(a) Cement

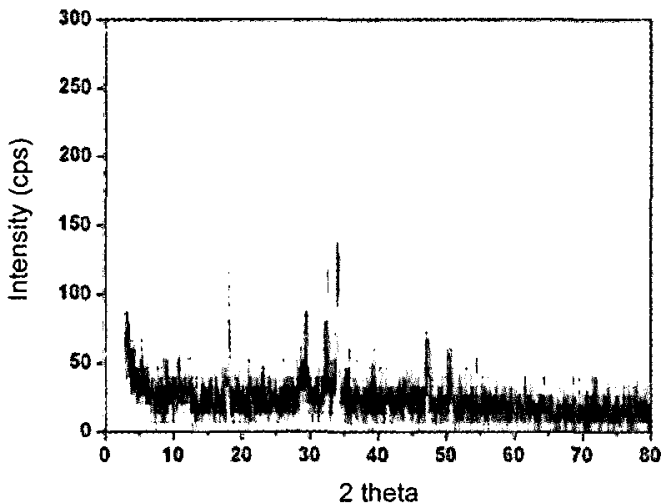

(c) $0 \%$

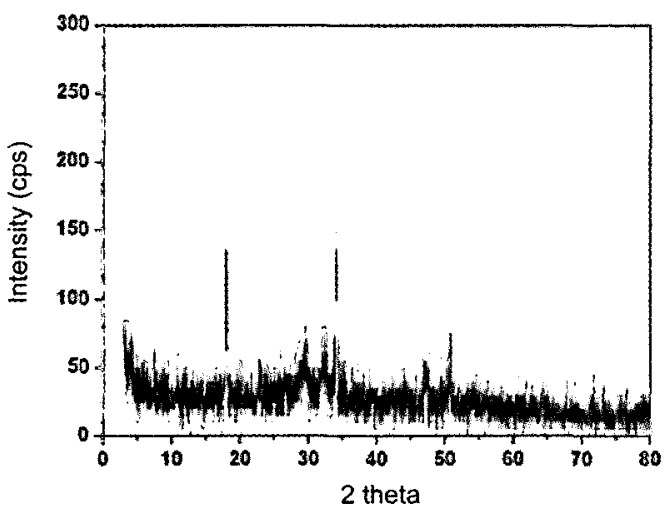

(e) $10 \%$

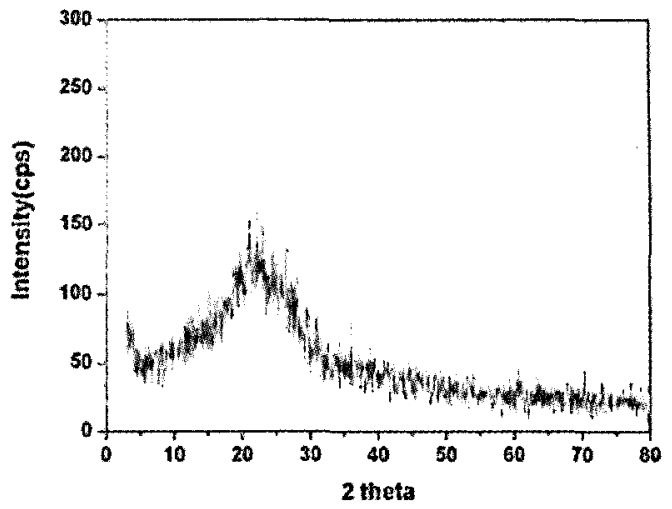

(b) Rice husk ash

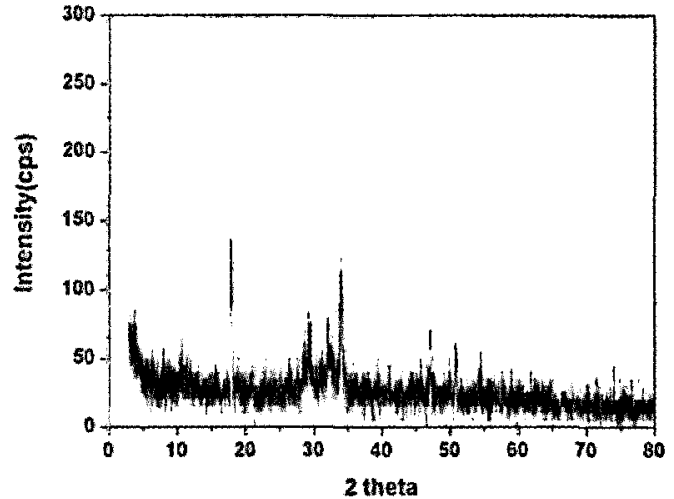

(d) $5 \%$

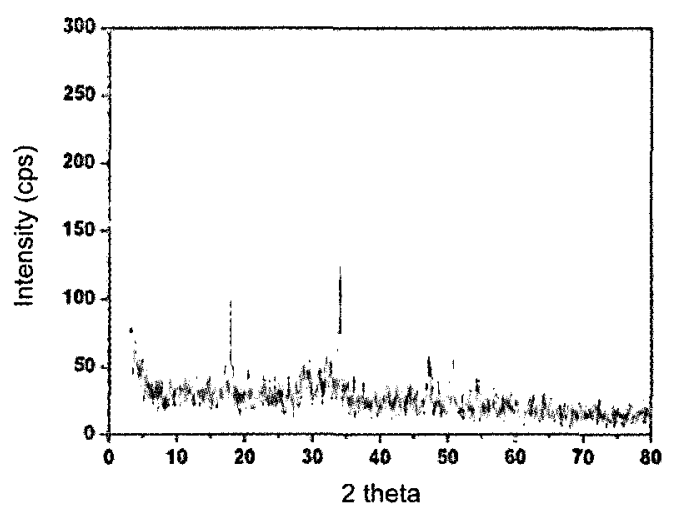

(f) $15 \%$

Fig. 1 XRD of cement mortar with content ratio of rice husk ash and cement

that of mortar without rice husk ash.

\section{Void ratio}

The most important factor in developing porous concrete used for planting purposes is to form continuous porosity to settle roots in the ground rapidly. Porosity for planting must be distributed diversely to settle roots in various positions and form a continuous linear orientation. In addition, porous concrete should be fabricated to include proper void ratio and continuous void in order 
to germinate and grow various plants. ${ }^{7,10)}$

Furthermore, it is important to guarantee void that is suitable for the environment where concrete is to be used because the void size and void ratio of planting concrete play an important role in the strength of concrete. ${ }^{6)}$

Fig. 2 shows void ratio according to the aggregate size and content ratio of rice husk ash. For an aggregate size of $5 \sim 10 \mathrm{~mm}$, the void ratio of porous concrete with rice husk ash was approximately $26.2 \sim 31.3 \%$ and decreased with increasing content ratio of rice husk ash. In addition, the porosity of porous concrete with content of rice husk ash decreased compared to porous concrete without rice husk ash registering a porosity of $33.6 \%$. This was because rice husk ash having a higher degree of powder than cement However, it was evident that the porous concrete exceeded target porosity of porous concrete in all mixtures and therefore considered optimal for planting and growing.

For an aggregate size of $10 \sim 20 \mathrm{~mm}$, the porosity of porous concrete with rice husk ash was approximately $29.4 \sim 34.2 \%$ and decreased with increasing the content ratio of rice husk ash. In addition, the porosity of porous concrete with content of rice husk ash decreased compared to porous concrete without rice husk ash registering a porosity of $36.4 \%$.

Furthermore, although porous concrete with a 5 10 mm aggregate exceeded target porosity, it was considered ideal for use with plants that have thin and long roots due to their small aperture. Moreover, because the aperture size and porosity of the porous concrete with a 10 20 $\mathrm{mm}$ aggregate performed better than porous concrete with a $5 \sim 10 \mathrm{~mm}$ aggregate, it was considered ideal for use with plants that have thick roots, such as bush clovers.

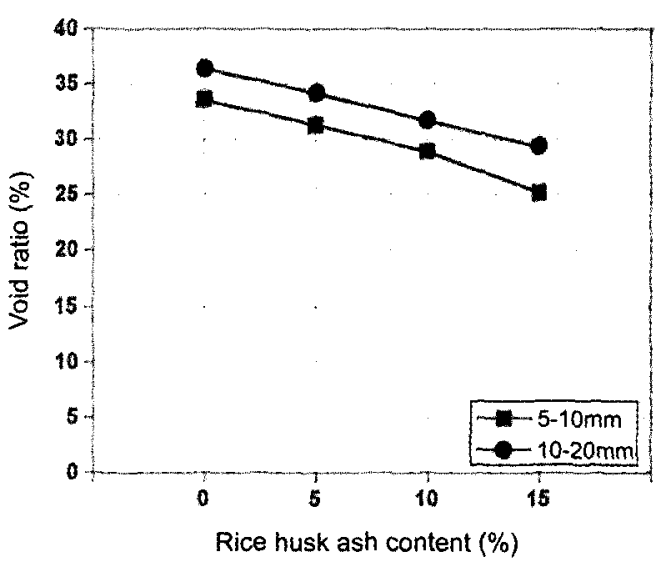

Fig. 2 Void ratio for Rice husk ash content

\section{Compressive strength}

The compressive strength of porous concrete used for planting purposes is significantly related to void size and void ratio.

Generally, Normal concrete revealed strength due to the adhesive force between cement pastes and aggregates. However, regarding porous concrete, a degree of contact in cement paste sheaths significantly affected the generation of compressive strength because the cement paste that formed the sheath of aggregate used in porous concrete generated strength based on the contact between coarse aggregates.

Fig. 3 illustrates the compressive strength of porous concrete according to aggregate size and content ratio of rice husk ash.

For an aggregate size of 5-10 mm, the compressive strength of porous concrete with rice husk ash was approximately $5.8 \sim 8.3 \mathrm{MPa}$ at 7 curing days. The compressive strength of porous concrete with a $5 \%$ and $10 \%$ content ratio of rice husk ash slightly increased compared to concrete without rice husk ash registered at 7.2 $\mathrm{MPa}$. In addition, the compressive strength of porous concrete with rice husk ash was approximately $7.9 \sim 10.2 \mathrm{MPa}$ at 28 curing days. 


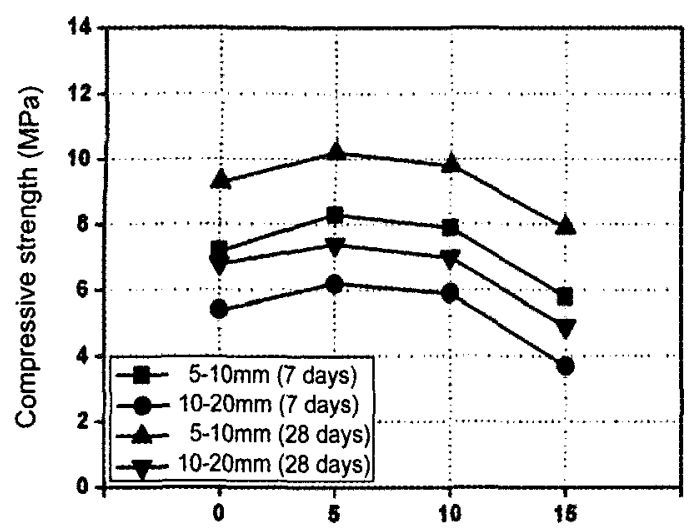

Rice husk ash content (\%)

Fig. 3 Compressive strength for Rice husk ash content

For an aggregate size of $10 \sim 20 \mathrm{~mm}$, the compressive strength of planting concrete with content of rice husk ash at 7 and 28 curing days was approximately $3.7 \sim 6.2 \mathrm{MPa}$ and $4.9 \sim 6.8$ $\mathrm{MPa}$, respectively. ${ }^{8)}$

According to the results of the XRD and SEM tests, the $\mathrm{SiO}_{2}$ that was a major chemical element of rice husk ash generated a large amount of calcium hydroxide in the early stage of the hydration process of cement leading to the formation of ettringite. Thus, strength generation was achieved on a large scale. ${ }^{4,5)}$

\section{Fexural strength}

Fig. 4 shows the flexural strength of porous concrete according to the aggregate size and content ratio of rice husk ash.

For an aggregate size of $5 \sim 10 \mathrm{~mm}$, the flexural strength of porous concrete with rice husk ash was approximately $1.3 \sim 2.3 \mathrm{MPa}$ at 7 curing days. The flexural of porous concrete with a $5 \%$ and $10 \%$ content ratio of rice husk ash such as compressive strength slightly increased compared to concrete without rice husk ash registered at $1.8 \mathrm{MPa}$.

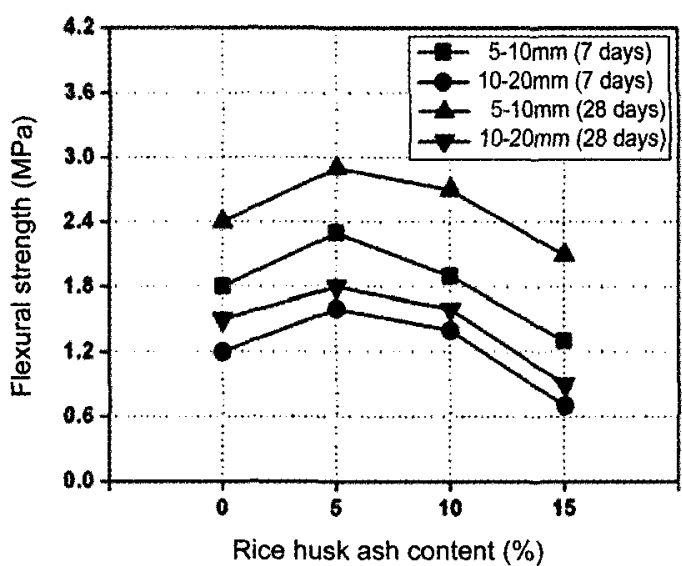

Fig. 4 Flexural strength for Rice husk ashcontent

In addition, the flexural strength of porous concrete with rice husk ash was approximately $2.1 \sim$ $2.9 \mathrm{MPa}$ at 28 curing days. Likewise, the flexural strength of porous concrete with a $5 \%$ and $10 \%$ content ratio of rice husk ash slightly increased compared to concrete without rice husk ash. Porous concrete with a $5 \%$ content ratio of rice husk ash demonstrated the greatest flexural strength. ${ }^{4,5)}$

For an aggregate size of $10 \sim 20 \mathrm{~mm}$, the flexural strength of planting concrete with rice husk ash at 7 and 28 curing days was approximately 0.7 $1.6 \mathrm{MPa}$ and $0.9 \sim 1.8 \mathrm{MPa}$, respectively.

\section{6. $\mathrm{pH}$}

Generally, hydrogen ion concentration in a solution is measured to identify either acidity or alkalinity. The value of concentration is expressed as a number between 1 and 14 by converting it into $\mathrm{pH}$ because hydrogen ion concentration registers large differences according to the type of solution. If $\mathrm{pH}$ values are less than 7 , it is recognized as acidity. Conversely, if $\mathrm{pH}$ values are more than 7 , it is recognized as alkalinity.

Although the $\mathrm{pH}$ value applied in planting is different according to the type of plants, $\mathrm{pH}$ levels are widely regarded as sufficient when 
5 8(maximum 9.5). In addition, it is important to reduce the leaching alkali concentration in planting in order to increase the germination rate in the early stage of growth and aid the growth of roots.

Porous concrete generates polybasic using the hydrogen ion included in the calcium hydroxide $\left(\mathrm{Ca}(\mathrm{OH})_{2}\right)$ generated in the hydration process therefore registering high $\mathrm{pH}$ of approximately 10 13 inhibiting growth unless employing special treatment.

Therefore, ammonium biphosphate was used to apply a neutral treatment in order to reduce the value of $\mathrm{pH}$ in porous concrete.

For an aggregate size of $5 \sim 10 \mathrm{~mm}$, the $\mathrm{pH}$ value of porous concrete with rice husk ash was approximately $9.36 \sim 9.59$ at 28 curing days with no neutral treatment. The $\mathrm{pH}$ value of porous concrete without rice husk ash was 9.68 representing a slight change in the $\mathrm{pH}$ value.

In the case of water curing with no neutral treatment, it was evident that the $\mathrm{pH}$ value continuously decreased to a specific level because the calcium hydroxide ion generated during hydration decomposed and continuously leached due to water molecules.

Furthermore, although the $\mathrm{pH}$ value of rice husk ash itself showed lower $\mathrm{pH}$ levels $(7 \sim 7.5)$ than average cement $(12.5 \sim 13.5), \mathrm{pH}$ values were low in spite of the decrease in the amount of cement because a large amount of calcium hydroxide was generated due to active hydration with cement in the hardening process of cement paste. ${ }^{1}$

The $\mathrm{pH}$ values for porous concrete with rice husk ash for a neutral treatment time of 1 day, 6 days, 13 days, and 20 days were 8.84 9.12, $8.86 \sim 9.12,9.08 \sim 9.23$, and 9.12 -9.22 , respectively, after 28 curing days. In addition, $\mathrm{pH}$ values of porous concrete without rice husk ash for a neutral treatment time were $9.15,9.17,9.28$, and 9.37, respectively. This showed that the $\mathrm{pH}$ value of porous concrete with rice husk ash slightly decreased.

For neutral treatment time performed for 1 curing day, the $\mathrm{pH}$ value significantly decreased with increasing curing days. In addition, the $\mathrm{pH}$ value rapidly decreased immediately after neutral treatment. Then, it gradually increased and decreased again after 14 days. However, the $\mathrm{pH}$ value was nearly the same regardless of neutral treatment time in 28 curing days.

Therefore, the results obtained in this test can be used to estimate the most appropriate planting time in porous concrete for planting application.

\section{Conclusions}

This study developed porous concrete with content of rice husk ash produced as an agricultural by-product and investigated various characteristics, such as void, compressive and flexural strengths, and $\mathrm{pH}$, according to the content ratio of rice husk ash, aggregate size, and neutral time using an SEM and XRD. The results of this study can be summarized as follows:

1) The SEM results for cement mortar with a $5 \%$ rice husk ash for the weight of cement formed more $\mathrm{C}-\mathrm{S}-\mathrm{H}$ hydrates due to the $\mathrm{SiO}_{2}$ present in the applied rice husk ash. In the $\mathrm{XRD}$ test, cement mortar with a $5 \%$ rice husk ash for the weight of cement registered a higher peak point of approximately $2 \theta=20 \sim 25^{\circ} \mathrm{com}^{-}$ pared to cement mortar without rice husk ash.

2) For content ratio of rice husk ash at 28 curing days and an aggregate size of $5 \sim 10 \mathrm{~mm}$ and $10 \sim 20 \mathrm{~mm}$, the void ratio of porous concrete was approximately $26.2 \sim 31.3 \%$ and $29.4 \sim$ $34.2 \%$, respectively. 
3) According to the content ratio of rice husk ash, the compressive strength of porous concrete for an aggregate size of $5 \sim 10 \mathrm{~mm}$ after 7 and 28 curing days was $5.8 \sim 8.3 \mathrm{MPa}$ and $7.9 \sim$ $10.2 \mathrm{MPa}$, respectively. In addition, for an aggregate size of $10 \sim 20 \mathrm{~mm}$, compressive strength of porous concrete was $3.7 \sim 6.2 \mathrm{MPa}$ and $4.9 \sim$ 6.8 $\mathrm{MPa}$, respectively.

4) According to the content ratio of rice husk ash for an aggregate size of $5 \sim 10 \mathrm{~mm}$ after 7 and 28 curing days, the flexural strength of porous concrete was $1.3 \sim 2.3 \mathrm{MPa}$ and 2.1 $2.9 \mathrm{MPa}$, respectively. In addition, for an aggregate size of $10 \sim 20 \mathrm{~mm}$, flexural strength of porous concrete was $0.7 \sim 1.6 \mathrm{MPa}$ and 0.9 $1.8 \mathrm{MPa}$, respectively.

5) Porous concrete with a $5 \%$ content of rice husk ash showed the highest compressive and flexural strength. In addition, porous concrete with content ratio of rice husk ash less than 10\% demonstrated higher strength levels than concrete without rice husk ash.

6) For neutral treatment, the $\mathrm{pH}$ value of porous concrete showed appropriate $\mathrm{pH}$ levels (less than 9.5) in all mixtures for planting at 28 curing days.

\section{References}

1. Benz. D. P. and E. J. Garboczi., 1992, Modelling the leaching of calcium hydroxide from cement paste : effects on pore space percolation and diffusivity, Materials and Structures $25: 523-533$.

2. Boateng, A. A and D. A. Skeete., 1990, Incineration of rice hull for use as a cementitious material : The Guyana Experience, Cement and Concrete Research 20(5) : 795-802.

3. Brandt. A. M, 1995, Cement-based composites
: materials, mechanical properties and performance, $E \& F N$ Spon : 66 .

4. Georgescu, Maria and Badanoiu, Alina., 1997, Hydration process in $3 \mathrm{CaO}$. $\mathrm{SiO}_{2}$-silica fume mixtures, Cement \& Concrete Composites 19(4) : 295-300.

5. Isaia. G. C., A. L. G. Gastaldini., and R. Morases., 2003, Physical and pozzolanic action of mineral additions on the mechanical strength of high-performance concrete, Cement \& Concrete Composites $25:$ :69-76.

6. Julian Salas, Marina Alvarez and Janer Veras., 1986, Lightweight insulating concretes with rice husk, The International Journal of Cement Composites and Lightweight Concrete 8(3): 171-180.

7. Malhotra, V. M., 1976, No-fines concrete-its properties and applications, state of art report, ACI Journal 73(11) : 628-644.

8. Mehta, P. K and K. J. Folliard., 1992, Ricehusk-ash, a uniques supplementary cementing material, advances in concrete technology, CANMET Publication : 407-432.

9. Moayad N, Alkhalaf and Hana A. Yousift., 1984, Use of rice husk ash in concrete, The International Journal of Cement Composites and Lightweight Concrete 6(4): 263-275.

10. Moayad N, Alkhalaf and A. Y. Halbod., 1986, Compactibility of no-fines concrete, The International Journal of Cement Composites and Lightweight Concrete 8(10) : 45-50.

11. Park, Kwang Su and Lee, Joon Gu., 1999, A study on manufacturing durable precast concrete products with rice husk ash, Rural research institute of korea rural community and agriculture corporation.

12. Swamy. R. N., 1986, Cement replacement materials(concrete technology and design), Surrey University Press 3 : 171-196. 